SHORT REPORT

\title{
A simple method for assessing if weight loss is greater or less than $10 \%$
}

\section{A Cohn}

G rowth, the paradigm marker of wellbeing in childhood, can be difficult to assess in the first two weeks of life. Some loss of weight is usual in the first few days, and distinguishing this from pathological weight loss can be difficult. Most paediatricians and midwives would become concerned if a baby lost greater than $10 \%$ of birth weight or, had failed to regain birth weight by 10 days of age.

Failure of breast feeding is becoming increasingly recognised as a major cause of pathological weight loss. This can lead to hypernatraemic dehydration which can be devastating. The evidence suggests that this condition is increasing in the UK. ${ }^{12}$

Weighing a baby and comparing current to birth weight provides the most practical, accurate measure of hydration. As breast fed babies may initially gain weight more slowly than bottle fed babies, there are concerns that weighing babies too often may undermine breast feeding and lead to its early cessation. ${ }^{2}$ Babies are therefore weighed only a few times in the first 10 days, and some cases of severe dehydration are thus overlooked.

I am also concerned about a small number of babies admitted with severe dehydration who have often been weighed in the previous few days, but the severity of weight loss has been overlooked due to arithmetic error. This is because midwives, after weighing a baby, are asked to calculate the percentage weight loss, which is a cumbersome equation involving many stages.

I propose a simple method to remedy this. Rather than thinking about weight lost one could concentrate on actual weight. (An infant that has lost more than $10 \%$ of birth weight will weigh less than $90 \%$ of birth weight.)

Labour wards could be provided with a stamp containing the following:

- Baby's weight should not fall below (birth weight $(\mathrm{kg}) \times$ $0.9)=$

The formula and result could be clearly placed on the mother's/baby's notes. Some information that initial mild weight loss is expected and that birth weight is normally regained by day 10 could also be helpful. If the metric weight is converted to imperial weight as well, this can provide further information to the parents who are more likely to use the latter, and may wish to weigh their baby themselveswhich is now easier with the widespread ownership of accurate weighing scales.

I believe that a simple tool like this could be useful in reducing this often devastating condition.

Correspondence to: Dr A Cohn, Department of Paediatrics, Watford General Hospital, Vicarage Road, Watford WD18 OHB, UK; anthony_cohn1@hotmail.com

Accepted 15 July 2004

\section{REFERENCES}

1 Laing IA, Wong M. Hypernatraemia in the first few days: is the incidence rising? Arch Dis Child Fetal Neonatal Ed 2002;87:F158-61.

2 Harding D, Cairns P, Gupta S, et al. Hypernatraemia: why bother weighing breast fed babies? Arch Dis Child Fetal Neonatal Ed 2001;85:F145. 